\title{
Estrogen Receptors and Signaling Pathways in Lactotropes and Somatotropes
}

\author{
Sandra Zárate Adriana Seilicovich \\ Instituto de Investigaciones en Reproducción, Facultad de Medicina, Universidad de Buenos Aires, \\ Buenos Aires, Argentina
}

\author{
Key Words \\ Estrogens - Estrogen receptors - Estrous cycle $\cdot$ Pituitary \\ Prolactin - Lactotropes $\cdot$ Growth hormone - Somatotropes • \\ Signaling pathways
}

\begin{abstract}
Estrogens are crucial determinants in the regulation of anterior pituitary function and maintenance of tissue homeostasis. Estrogen actions in this gland are exerted through both classical and non-classical mechanisms of action. This review summarizes the expression of classical $\alpha$ - and $\beta$-estrogen receptors and variant isoforms of estrogen receptors in anterior pituitary cell subpopulations. We also analyze estrogen receptor signaling pathways involved in estrogenic actions in the anterior pituitary gland, especially in lactotropes and somatotropes. Complex interactions between multiple signaling pathways are involved in estrogen regulation of hormone secretion, cell proliferation and cell death in this gland. Insight into these pituitary responses to estrogens would help to understand pituitary function and tumorigenesis.
\end{abstract}

Copyright $\odot 2010$ S. Karger AG, Basel

Estrogens regulate gene expression and influence crucial physiological events in target tissues. They are also essential for reproductive functions in the female, stimulating secretion of gonadotropins and prolactin $[1,2]$. Estrogens also play an important role in anterior pituitary remodeling in several physiological conditions such as pregnancy, lactation and the estrous cycle [3].

The expression of estrogen receptor (ER) forms and other proteins interacting with the receptor markedly influences overall activity of estrogens in a given cell. Genomic effects of estrogens as well as factors determining estrogen action in the hypothalamic-pituitary axis were reviewed several years ago [4]. Since then, information on classical ERs and particularly on intracellular signaling pathways involved in non-classical mechanisms of estrogen action in the anterior pituitary gland has grown. This review is an updated summary of mechanisms of estrogen action in anterior pituitary cells, mainly in rodent experimental models.

\section{Estrogen Receptor Structure}

Most biological actions of estrogens take place through ERs. The two classical ERs, ER $\alpha$ and ER $\beta$, belong to the superfamily of nuclear receptors, specifically the family of steroid receptors that act as ligand-regulated transcription factors [5]. These ER isoforms are encoded by separate genes located on different chromosomes [6]. ERs are composed of an N-terminal region domain, a DNA-binding domain, a hinge domain, a ligand-binding domain and a C-terminal domain. ERs act as dimers and their transcriptional activity is mediated by synergy between two activation domains, a constitutively active AF-1 at

\section{KARGER \\ Fax +4161306 1234 \\ E-Mail karger@karger.ch}

www.karger.com (c) 2010 S. Karger AG, Basel

$0028-3835 / 10 / 0924-0215 \$ 26.00 / 0$

Accessible online at:

www.karger.com/nen
Adriana Seilicovich

Instituto de Investigaciones en Reproducción

Facultad de Medicina, Universidad de Buenos Aires

Paraguay 2155, piso 10, Buenos Aires ABG1121 (Argentina)

Tel./Fax +54 115950 9612, E-Mail adyseili@fmed.uba.ar 
the $\mathrm{N}$ terminus and a ligand-dependent AF-2 in the ligand-binding domain [7].

ER $\alpha$ and ER $\beta$ are more than 95\% homologous in the DNA-binding domain and about $59 \%$ in the ligand-binding domain, but differ in the C-terminal domain and the $\mathrm{N}$-terminal transactivation domain [6]. The $\mathrm{N}$-terminal domain is the most variable region, suggesting that these two isoforms might interact differently with proteins, thereby contributing to ER subtype-specific action on target genes [7].

Receptor activation by $17 \beta$-estradiol $\left(\mathrm{E}_{2}\right)$ requires a conformational change in the ligand-binding domain that includes formation of a hydrophobic pocket and modification of the surface that facilitates interaction with coregulatory proteins that may either enhance or suppress ER-dependent transcriptional activity [5]. Many coregulators are enzymes that modify proteins through several mechanisms, including acetylation, methylation, phosphorylation and chromatin remodeling at sites where ERs are attached $[5,7,8]$. Coactivators such as steroid receptor coactivator-1 (SRC-1), SRC-2 and SRC-3 increase ER-mediated transcription by chromatin remodeling through histone acetyltransferase activity and recruitment of other coactivators, including CREB-binding protein (CBP) and p300/CBP-associated factor [8]. Histone methylation, catalyzed by histone methyltransferases and reversed by histone demethylases, also modulates nuclear hormone signaling [9]. Corepressors suppress or silence gene expression by methylation of DNA and by binding to methyl-CpG-binding proteins that recruit corepressor complexes and histone deacetylase. Some corepressors of nuclear receptors are the nuclear receptor corepressor (NcoR), the silencing mediator of retinoid and thyroid hormone receptors (SMRT) and the repressor of ER activity (REA). Nuclear receptor coregulators are molecules critical for modulating steroid-receptor-mediated transcription. The capacity of ERs to recruit different coregulators may explain cell-specific responses to estrogens [8].

Several variant isoforms of ER mRNAs and proteins exist for both ER $\alpha$ and ER $\beta$ subtypes [7]. The splice variants could result from deletion of one or more coding exons or base insertion within an exon [4]. Truncated estrogen receptor products 1 and 2 (TERP-1 and TERP-2) are truncated forms of ER $\alpha$ lacking the N-terminal, DNA-binding and hinge regions and part of the hormone-binding domain but contain specific upstream sequences [4]. In physiological conditions in the female rat, TERP-1 expression is limited to the pituitary [4]. TERP-1 cannot bind to DNA and thereby does not affect gene ex- pression by itself but can modulate the action of fulllength ERs, depending on cell and promoter context [4]. TERP-1 forms heterodimers with either ER $\alpha$ or ER $\beta$. With high TERP-1:ER $\alpha$ ratios, TERP-1 can dimerize with $\mathrm{ER} \alpha$, inhibiting $\mathrm{ER} \alpha$ from binding to its DNA response elements [10]. TERP-1 can also suppress ER $\alpha$ transcriptional activity by competition for coactivators such as SRC-1 [10]. On the other hand, TERP-1 at low concentrations can stimulate $\mathrm{ER} \alpha$ transcriptional activity by titration of corepressors such as REA [11].

Although classical ERs are located mostly in the nucleus, estrogen-binding proteins have also been localized in extranuclear compartments, such as the plasma membrane, mitochondria and the endoplasmic reticulum [12, 13]. Since the first identification of specific binding sites for estrogen at the outer surface of endometrial cells over 30 years ago [14], considerable research has been done on this area, defining key aspects of the nature and functions of extranuclear ERs. Although ER $\alpha$ and ER $\beta$ present at the membrane could be transmembrane proteins, these receptors are more generally accepted to be membraneassociated, anchored by scaffold proteins to the inner leaflet of the membrane $[12,13,15]$. Palmitoylation of a residue in the ligand-binding domain promotes association of ER with caveolin-1, a necessary transporter of $\mathrm{ER} \alpha$ to caveolae rafts in the plasma membrane $[12,13]$. ERs are considered a central component of a membrane complex containing several molecules including G-proteins, heat-shock protein 90, c-Src homology, collagen homology (Shc) and modulator of non-genomic activity of the ER (MNAR), which are critical in rapid estrogenic actions [13]. A small fraction of ERs is localized within mitochondria [16]. Mitochondrial ER was reported to decrease reactive oxygen species production by activation of MnSOD [16]. The orphan G-protein-coupled receptor (GPR30), a controversial ER reported to be localized at the plasma membrane and the endoplasmic reticulum $[17,18]$, failed to stimulate estrogen actions and therefore may not be an ER [13].

\section{Regulation of the Expression of Estrogen Receptors and Receptor Variants in the Pituitary}

Cell-specific actions of estrogens in the rat pituitary can result from modulated expression of ER isoforms. The anterior pituitary gland of the adult female rat expresses classical ERs, ER $\alpha$ and ER $\beta$, and TERP-1. Both $\mathrm{ER} \alpha$ and $\mathrm{ER} \beta$ are transcribed from several alternate first exons and multiple promoters whereas TERP-1 is tran- 
scribed from a promoter different from those for ER $\alpha$ [4]. $\mathrm{ER} \alpha$ was reported to be expressed in varying proportions in all the secretory populations of the anterior pituitary as well as in folliculo-stellate cells $[19,20]$. ER $\alpha$ is localized mainly in lactotropes, followed by somatotropes and gonadotropes. The percentage of ER $\beta$-expressing cells is lower than that of ER $\alpha$-bearing cells and only a small proportion of pituitary cells coexpresses both receptors [19, 20]. In humans, $\mathrm{ER} \alpha$ was not detected in $\mathrm{GH}$-producing cells [4]. The rat pituitary also expresses TERP-1 and TERP-2 mRNA, which have not been detected in other tissues. TERP-1 protein is localized primarily in lactotropes and gonadotropes [19].

Strong evidence indicates that ER $\alpha$ expression varies during the estrous cycle with its highest expression at proestrus whereas ER $\beta$ mRNA levels were found to remain relatively constant in rats $[20,21]$ or to be higher at proestrus than at diestrus in bitches [22]. Conversely, $\mathrm{ER} \alpha$ mRNA was reported not to change significantly across the estrous cycle whereas ER $\beta$ levels fall in the morning of proestrus [4]. ER $\alpha$ expression is higher in female rats than in males [4]. TERP-1 mRNA begins to rise at diestrus and peaks at proestrus. Estrogen treatment of ovariectomized rats does not regulate $\mathrm{ER} \alpha$ transcription and slightly decreases ER $\beta$ mRNA levels but dramatically induces TERP-1 mRNA [23]. Through ER $\alpha$, endogenous estrogens differentially regulate expression of mRNAs by encoding several ER isoforms [24]. Both ER $\alpha$ and the pituitary-specific transcription factor Pit-1 act at the proximal promoter region of TERP-1 gene and are essential for full promoter activity [25].

Classical ERs and TERP-1 proteins are also modulated by gonadal steroids [4]. TERP-1 protein levels increase dramatically with estrogens and thus the TERP-1:ER $\alpha$ protein ratio can be very high at proestrus [4]. Although $\mathrm{ER} \alpha$ expression is relatively constant during pregnancy and lactation, TERP-1 expression is highly increased in mid- to late pregnancy [26]. It was also demonstrated that TERP- 1 mRNA and protein are stimulated by $\mathrm{E}_{2}$ in pituitary cell lines such as $\mathrm{GH} 3$ somatolactotrope cells, MMQ lactotrope cells and L $\beta$ T2 gonadotrope cells $[25,27]$.

Estrogen-binding proteins associated with the plasma membrane have been detected in the anterior pituitary gland [28]. Membrane-associated $\mathrm{ER} \alpha(\mathrm{mER} \alpha)$ was found in GH3 [29] and in normal lactotropes [30, 31], whereas mER $\beta$ was not found in these cells [30]. $\mathrm{mER} \alpha$ was also detected in the plasma membrane of somatotropes [31]. Expression of $\mathrm{mER} \alpha$ in lactotropes is higher at proestrous than at diestrus and is estrogen-dependent [Zárate et al., unpubl. results].

Mechanisms of Estrogen Action in the Pituitary

\section{Mechanisms of Estrogen Action}

ERs signal through multiple pathways, which can be classified as either classical, involving specific estrogen response element- (ERE), or non-classical, involving ERE-independent mechanisms [32]. The classical mechanism of estrogen action involves binding of estrogens to intracellular ERs, induction of conformational changes in the receptor leading to dimerization, interaction with coregulator molecules and binding of this complex to ERE- or ERE-like sequences in the regulatory regions of target genes to either activate or repress gene expression. Non-classical, ERE-independent pathways of estrogen action include: (1) regulation of gene expression via protein-protein interactions between ligand-bound ERs and other transcription factors such as SP-1, c-Fos/c-Jun B (AP-1) and NF- $\kappa$; (2) ligand-independent ER signaling, in which second-messenger pathways modify the activity of intracellular kinases and phosphatases that alter the state of phosphorylation and transcriptional activity of ERs, and (3) rapid, membrane-initiated estrogen actions in which activation of membrane-associated ERs initiate second-messenger pathways that modulate the phosphorylation status and hence the activity of cytoplasmic proteins such as Bax or eNOS as well as other transcription factors such as cAMP response element-binding protein (CREB) [33]. In this way, through membrane initiated pathways, estrogens can regulate transcription indirectly [32]. Studies in recent years suggest a high degree of interaction between membrane-initiated signaling pathways and both classical and non-classical intracellular signaling pathways to ultimately accomplish a physiological end-point [34] (fig. 1).

Multiple molecular mechanisms are involved in estrogen-induced hormone synthesis and release, cell proliferation and death in the pituitary. Estrogen actions on gonadotropes are well documented and reviewed elsewhere [1]. Considering that lactotropes are the anterior pituitary cell population with the highest turnover during the estrous cycle followed by somatotropes, the mechanisms of estrogen action on these pituitary populations will be discussed.

\section{Prolactin Secretion}

Estradiol is a major regulator of prolactin (PRL) secretion [35]. Within the rat anterior pituitary, estradiol controls PRL gene expression by direct binding of activated ERs to specific DNA sequences located in the promoter of the rat PRL (rPRL) gene [35]. Also, the rPRL gene contains multiple binding sites for Pit-1 protein [2], which is

Neuroendocrinology 2010;92:215-223 


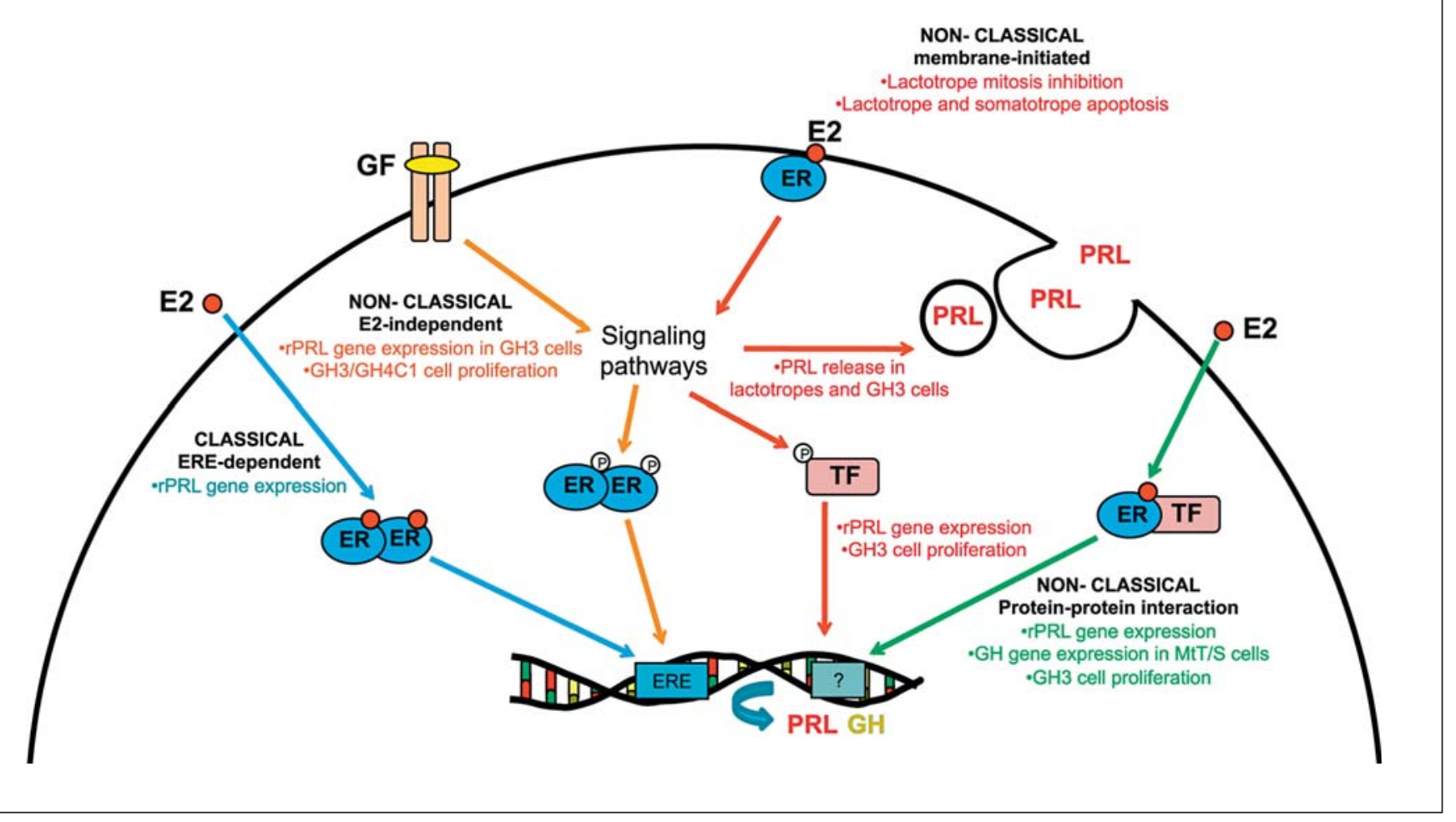

Fig. 1. Mechanisms of estrogen action via ERs in the pituitary. ER signaling includes: classical ERE-dependent, in which liganded ER dimerizes and binds to ERE- or ERE-like sequences in the promoter of target genes; non-classical ligand-independent, in which the ER is activated by phosphorylation in the absence of $\mathrm{E}_{2}$; non-classical membrane-initiated, in which an activated membrane-associated ER initiates second-messenger pathways that phosphorylate different proteins including transcription factors; non-classical protein-protein interaction, in which the liganded ER interacts with other transcription factors bound to their response elements in the DNA. Some examples of estrogen actions in the pituitary are shown under the corresponding mechanism. $\mathrm{E}_{2}=17 \beta$-Estradiol; ER = estrogen receptor; ERE = estrogen response element; $\mathrm{GF}=$ growth factor; $\mathrm{TF}=$ transcription factor; ?= unknown transcription factor response element; PRL = prolactin; $\mathrm{GH}=$ growth hormone. For details, see text. required for both basal as well as estrogen-induced PRL gene expression $[36,37]$. The development of cell lines derived from pituitary tumors has largely contributed to the study of PRL secretion at the cellular and molecular level. However, the functional heterogeneity of cell lines raises the concern of considering them as representing normal lactotropes. For instance, different GH3 cell subclones can release GH only, PRL only, both hormones or neither [35]. Thus, data collected from cell lines must be considered carefully when drawing conclusions that apply to normal lactotropes. An estrogen-dependent physical interaction between ER and Pit-1 protein has been shown in GH3 and PR1 lactotrope cell lines [38]. The rPRL promoter also contains binding sites for other transcription factors, some of whose functions are regulated by protein kinases activated by MAPK and/or PKA pathways, suggesting a possible role of non-classical estrogen regulation of gene expression through ERE-independent pathways. It was reported that $\mathrm{E}_{2}$-induced rapid and transient activation of ERK1/2 by a mechanism likely involving c-Raf-1 is required for PRL gene transcription in both GH3 and PR1 cells [39]. Direct phosphorylation of a MAPK-responsive transcription factor and changes in the phosphorylation status of ER by MAPKs are mechanisms suggested to be involved in $\mathrm{E}_{2}$-induced PRL gene expression in these cells [39]. Recently, EGF through ErbB1 activation was reported to cross-talk with ER $\alpha$ to stimulate PRL gene expression in GH3 cells. This EGF action is mediated by ERK1/2-induced S118 phosphorylation of $\mathrm{ER} \alpha$, indicating that non-classical, ligand-independent ER signaling is involved in EGF-induced PRL expression in these cells [40]. Another recent report also showed interaction between bone morphogenetic protein-4 (BMP-4) and estrogen intracellular signaling path- 
ways with a direct effect on PRL gene expression in GH3 cells. BMP- $4 / \mathrm{E}_{2}$ cross-talk on PRL transcriptional activity is mediated by the binding of a complex between Smad-1 and ER to a Smad-binding sequence on the PRL promoter. This novel signaling mechanism was shown to be specific for PRL regulation rather than a general effect, since no BMP-4/E $\mathrm{E}_{2}$ cross-talk was observed on $\mathrm{GH}$ secretion [41]. Recent studies in GH3 cells have shown that a functional $E R \alpha$ is essential for the maintenance of basal intracellular PRL levels, and that occupation rather than degradation of $E R \alpha$ by an antagonist is sufficient to inhibit PRL gene expression [42, 43].

On the other hand, the control of PRL gene expression by ER $\beta$ has not been extensively studied. Since the mouse pituitary does not express ER $\beta$, PRL production is unaltered in ER $\beta$-deficient (ER $\beta K O)$ mice whereas it is impaired in ER $\alpha \mathrm{KO}$ mice [44]. However, since rat and human pituitaries express both ERs, estrogen regulation of PRL expression is likely to be different in mice versus rats and humans and should be re-examined. In fact, overexpression of ER $\beta$ results in $\mathrm{E}_{2}$-induced PRL promoter activity in $\mathrm{GH} 3$ cells, suggesting a potential role of this receptor in the control of PRL gene expression [2].

In the absence of an available human pituitary cell line, most studies regarding the transcriptional regulation of the human PRL (hPRL) gene have been performed by transfecting the hPRL promoter into GH3 cells. Taking into account that the rat pituitary cellular milieu may differ from the human's and that cell lines are functionally dissimilar to primary cultures of pituitary cells, the observed effects may not be a reflection of what happens in the human pituitary in physiological conditions. Humans are not as responsive to the effects of estrogens on PRL expression as rats [2]. This discrepancy between estrogen effects on rPRL and hPRL gene expression has been attributed to differences in the nucleotide sequence between rat and human EREs, which would lead to impaired ERE function in the hPRL promoter [45]. It was suggested that despite a relatively small effect per se of estrogens in humans, they are nonetheless key factors to hPRL expression acting in concert with other endocrine or paracrine signals in the pituitary [46].

An additional regulatory level of estrogen effects on PRL secretion beyond gene expression is PRL release, with seeming involvement of non-classical, membraneinitiated estrogen actions. Physiological concentrations of $\mathrm{E}_{2}$ or $\mathrm{E}_{2}$ bound to $\mathrm{BSA}$ ( $\mathrm{E}_{2}-\mathrm{BSA}$ ), a conjugate unable to permeate the plasma membrane, were found to induce a rapid release of PRL from a subset of lactotropes through a cAMP-PKA independent pathway. This rapid PRL-se-

Mechanisms of Estrogen Action in the Pituitary cretagogue effect of estrogens is achieved independently of DNA transcription or RNA translation and does not seem to involve classical nuclear receptors [28]. Another study suggested that the activation of PKC signaling pathway through $\mathrm{mER} \alpha$ is involved in PRL release from lactotropes in culture [30]. Rapid induction of PRL release from GH3 cells has also been reported [45]. Rapid, concentration-dependent increase in intracellular calcium levels and PRL release induced by $\mathrm{E}_{2}$ and some xenoestrogens in GH3/B6 cell sublines heavily depend on the presence of $m E R \alpha[48,49]$ and may involve $E_{2}$-induced ERK phosphorylation [50, 51].

\section{Growth Hormone Secretion}

Although the involvement of estrogens in the synthesis and release of GH from the anterior pituitary is well accepted, it is still unclear whether they regulate these actions by acting directly on somatotropes or through modulation of hypothalamic factors controlling $\mathrm{GH}$ secretion [52]. Changes in circulating levels of sex steroids modulate GH secretion in many species, which accounts for sexual dimorphism in its secretory pattern $[52,53]$. In the rat, there are changes in the expression of GH mRNA during the estrous cycle that can be positively correlated with changes in circulating $\mathrm{E}_{2}$ [54]. In cultured anterior pituitary cells from female rats, physiological concentrations of $\mathrm{E}_{2}$ increase spontaneous and $\mathrm{GH}$-releasing hormone (GHRH)-induced GH release as well as cellular GH content [55]. More recently, physiological concentrations of $E_{2}$ were shown to increase the percentage of GH antigen-bearing cells and of cells that express $\mathrm{GH}$ mRNA or GHRH receptors in vitro [53]. Also, xenoestrogens were reported to induce $\mathrm{GH}$ mRNA and protein expression via an ER-mediated pathway both in vivo and in cultured $\mathrm{GH} 3$ cells $[56,57]$. In the $\mathrm{MtT} / \mathrm{S}$ somatotrope cell line, which expresses ER $\alpha$ but not ER $\beta$, estrogens stimulate the transcription of the $\mathrm{GH}$ gene by acting at its proximal promoter [58]. Since two Pit-1-binding sites but no ERE are found in this region, it has been suggested that ER might be acting through protein-protein interaction between Pit-1 and ER, similarly to one of the mechanisms described in the rPRL gene promoter $[38,58]$.

\section{Cell Proliferation and Death}

It is generally accepted that estrogens act as powerful mitogens, exerting a sustained, dose-dependent trophic stimulus on anterior pituitary mitotic activity, which is ultimately responsible for the slightly larger pituitary in females compared to males and in parous compared to nulliparous females, as well as the induction of prolacti- 
nomas in some rodent models. However, strong evidence supports the view that prolonged estrogen treatment in humans does not necessarily result in either hyperprolactinemia, pituitary hyperplasia or progression to prolactinoma $[2,59]$. In fact, a recent report using female Wistar rats has shown that the mitotic effect of estrogens in the anterior pituitary is transient and does not lead to persistent pituitary growth [60].

It is well established that estrogens are able to induce pituitary tumors, most of which are PRL- or GH-secreting tumors, only in certain rat strains or mice models [reviewed in 61]. Fisher 344 rats are highly responsive to estrogens, developing prolactinomas within weeks of estrogen treatment [61]. Mechanisms that mediate estrogen action on lactotrope cell growth and prolactinoma formation in this rat strain involve down-regulation of D2 receptors, up-regulation of TGF $\beta$ isoforms and other growth factors released by folliculo-stellate cells which act on lactotropes in a paracrine manner [61]. Also, the suppression of inhibitory $\mathrm{G}(\mathrm{Gi})$ proteins and the increase in stimulatory $G(\mathrm{Gs})$ proteins has been suggested as a mechanism for estrogen action on lactotrope cell growth and hormone production in Fisher 344 rats [62]. In lactotrope cell lines, proliferation is more sensitive to estrogen treatment than PRL synthesis, since $\mathrm{E}_{2}$ induces proliferation at much lower concentrations than those required to stimulate PRL gene expression [63]. Although most estrogen actions on anterior pituitary cell proliferation appear to be mediated by ER $\alpha[42,64]$, TERP has also been suggested as a candidate responsible for the regulation of PR1 cell hypersensitive growth [63]. It was recently reported that $\mathrm{ER} \alpha$ proteosome-mediated degradation must follow antagonist occupation of the receptor to suppress GH3 cell proliferation [43]. A recent report has shown that EGF via activation of ErbB1 interacts with ligand-occupied $\mathrm{ER} \alpha$ to induce $\mathrm{GH} 3$ cell proliferation [64]. Also, the cross-talk between BMP4 and estrogens results in stimulation of GH3 cell proliferation probably through induction of the cell cycle regulator c-Myc [65]. Recently, $\mathrm{E}_{2}$ as well as weaker estrogens such as estrone and estriol, and some phytoestrogens were reported to elicit a proliferative response in the mER $\alpha$-enriched pituitary tumor cell line $\mathrm{GH} 3 / \mathrm{B} 6 / \mathrm{F} 10$, an effect likely involving this membrane receptor as well as MAPK signaling pathways and downstream transcription factor activation $[66,67]$.

Most in vitro studies investigating effects of estrogens on pituitary cell growth have used estrogen-responsive cell lines. However, estrogen regulation of proliferation in tumor cell lines may not be representative of the normal physiology of anterior pituitary cell proliferation. Estro- gen-induced lactotrope proliferation in primary culture seems to be a process regulated by complex interactions between different intracellular signal transduction pathways involving ER, PKA, and MAPK [68]. Strong evidence supports that $\mathrm{E}_{2}$ exerts mitogenic and antimitogenic actions in a cell-context and time-dependent manner. The well-established mitogenic action of $E_{2}$ occurs only with long incubation periods and requires the synthesis of local mediators whereas $\mathrm{E}_{2}$ antimitogenic action has a short latency and needs the presence of growth factors [68]. It has been suggested that $\mathrm{E}_{2}$ acts selectively in signaling pathways of growth factors to counteract their mitogenic action [69]. Also, the early mitogenic activity promoted by insulin on lactotropes is blocked by $\mathrm{E}_{2}$ or $\mathrm{E}_{2}$-BSA, an action involving PKC, ERK1/2, Pit-1 and probably $m E R \alpha[30]$. Another study using lactotrope-enriched cells demonstrated that estrogens influence lactotrope proliferation independently of paracrine signals from other pituitary cell types probably through an autocrine mechanism involving growth factors produced by lactotropes themselves [70]. Although it was originally suggested that the cross-talk between growth factor and ER signaling pathways was mediated by ligand-independent growth factor activation of ER [68], a recent report has demonstrated the absence of such a mechanism in normal pituitary cells in culture, suggesting that ligandindependent ER activation is a specific event likely restricted to pituitary transformed cells such as GH3 and GH4C1 cells [71].

Estrogens have also been shown to modulate apoptosis of anterior pituitary cells, particularly lactotropes and somatotropes, through different mechanisms involving both extrinsic and intrinsic apoptotic pathways [reviewed in 72]. The apoptotic action of the TNF- $\alpha /$ TNFR 1 and Fas/FasL systems as well as dopamine in the anterior pituitary are estrogen-dependent [73-75]. One mechanism involved in the estrogenic sensitization of anterior pituitary cells to apoptosis includes an increase in the expression of Fas/FasL and TNF- $\alpha /$ TNFR1 $[74,76]$. Also, $E_{2}$ per se induces apoptosis of anterior pituitary cells via changes in the balance of pro- and antiapoptotic proteins of the Bcl-2 family and through activation of membrane-associated $\mathrm{ER} \alpha[31,77]$.

\section{Concluding Remarks}

Although estrogens have traditionally been thought to exert their multiple actions exclusively through activation of receptors acting as nuclear, ligand-dependent 
transcription factors, it is now well accepted that the molecular mechanisms of estrogen action in the pituitary are more complex and involve interactions between multiple players. The activation of cytoplasmic/nuclear and membrane ERs by estrogens or even other ligands initiates diverse intracellular signaling pathways which are not mutually exclusive but interact with each other to contribute to the overall effect of estrogens on hormone secretion, cell proliferation and death in the pituitary. However, most studies are performed in cell lines and may not re- flect the physiology of the normal pituitary, which raises concerns about drawing conclusions regarding normal cell behavior based on data from cell lines.

\section{Acknowledgments}

This work was supported by grants from the Agencia Nacional de Investigaciones Científicas y Tecnológicas, CONICET and the University of Buenos Aires, Argentina.

\section{References}

1 Childs GV: Gonadotropes and lactotropes; in Neill JD (ed): Physiology of Reproduction. Amsterdam, Elsevier, 2006, pp 1483-1580.

$\checkmark 2$ Ben-Jonathan N, LaPensee CR, LaPensee EW: What can we learn from rodents about prolactin in humans? Endocr Rev 2008;29: $1-41$.

-3 Zárate S, Zaldivar V, Jaita G, Magri L, Radl D, Pisera D, Seilicovich A: The role of estrogens in anterior pituitary gland remodeling during the estrous cycle. Front Horm Res 2010;38:25-31.

4 Shupnik MA: Oestrogen receptors, receptor variants and oestrogen actions in the hypothalamic-pituitary axis. J Neuroendocrinol 2002;14:85-94.

5 Morani A, Warner M, Gustafsson JA: Biological functions and clinical implications of oestrogen receptors $\alpha$ and $\beta$ in epithelial tissues. J Intern Med 2008;264:128-142.

-6 Kuiper GG, Carlsson B, Grandien K, Enmark E, Häggblad J, Nilsson S, Gustafsson JA: Comparison of the ligand binding specificity and transcript tissue distribution of estrogen receptors $\alpha$ and $\beta$. Endocrinology 1997; 138:863-870.

7 Heldring N, Pike A, Andersson S, Matthews J, Cheng G, Hartman J, Tujague M, Ström A, Treuter E, Warner M, Gustafsson JA: Estrogen receptors: how do they signal and what are their targets. Physiol Rev 2007;87:905931.

8 Tetel MJ, Auger AP, Charlier TD: Who's in charge? Nuclear receptor coactivator and corepressor function in brain and behavior. Front Neuroendocrinol 2009;30:328-342.

\$ Wu SC, Zhang Y: Role of protein methylation and demethylation in nuclear hormone signaling. Mol Endocrinol 2009;23:1323-1334.

10 Resnick EM, Schreihofer DA, Periasamy A, Shupnik MA: Truncated estrogen receptor product-1 suppresses estrogen receptor transactivation by dimerization with estrogen receptors $\alpha$ and $\beta$. J Biol Chem 2000;275: $7158-7166$
11 Lin VY, Resnick EM, Shupnik MA: Truncated estrogen receptor product-1 stimulates estrogen receptor- $\alpha$ transcriptional activity by titration of repressor proteins. J Biol Chem 2003;278:38125-38131.

$12 \mathrm{Kim} \mathrm{KH}$, Bender JR: Membrane-initiated actions of estrogen on the endothelium. Mol Cell Endocrinol 2009;308:3-8.

13 Levin ER: Plasma membrane estrogen receptors. Trends Endocrinol Metab 2009;20:477482.

14 Pietras RJ, Szego CM: Specific binding sites for oestrogen at the outer surfaces of isolated endometrial cells. Nature 1977;265:69-72.

15 Bondar G, Kuo J, Hamid N, Micevych P: Estradiol-induced estrogen receptor- $\alpha$ trafficking. J Neurosci 2009;29:15323-15330.

16 Yager JD, Chen JQ: Mitochondrial estrogen receptors - new insights into specific functions. Trends Endocrinol Metab 2007;18:8991.

17 Filardo E, Quinn J, Pang Y, Graeber C, Shaw $S$, Dong J, Thomas P: Activation of the novel estrogen receptor G-protein-coupled receptor 30 (GPR30) at the plasma membrane. Endocrinology 2007; 148:3236-3245.

18 Otto C, Rohde-Schulz B, Schwarz G, Fuchs I, Klewer M, Brittain D, Langer G, Bader B, Prelle K, Nubbemeyer R, Fritzemeier KH: Gprotein-coupled receptor 30 localizes to the endoplasmic reticulum and is not activated by estradiol. Endocrinology 2008; 149:48464856

19 Mitchner NA, Garlick C, Ben-Jonathan N: Cellular distribution and gene regulation of estrogen receptors $\alpha$ and $\beta$ in the rat pituitary gland. Endocrinology 1998;139:39763983.

20 González M, Reyes R, Damas C, Alonso R, Bello AR: Oestrogen receptor $\alpha$ and $\beta$ in female rat pituitary cells: an immunochemical study. Gen Comp Endocrinol 2008;155:857868.

21 Childs GV, Unabia G, Komak S: Differential expression of estradiol receptors $\alpha$ and $\beta$ by gonadotropes during the estrous cycle. J Histochem Cytochem 2001;49:665-666.
22 Hatoya S, Torii R, Kumagai D, Sugiura K, Kawate N, Tamada H, Sawada T, Inaba T: Expression of estrogen receptor $\alpha$ and $\beta$ genes in the mediobasal hypothalamus, pituitary and ovary during the canine estrous cycle. Neurosci Lett 2003;347:131-135.

23 Bryant WM, Gibson MA, Shupnik MA: Stimulation of the novel estrogen receptor- $\alpha$ intronic TERP-1 promoter by estrogens, androgen, pituitary adenylate cyclase-activating peptide, and forskolin, and autoregulation by TERP-1 protein. Endocrinology 2006;147:543-551.

24 Tena-Sempere M, Navarro VM, Mayen A, Bellido C, Sánchez-Criado JE: Regulation of estrogen receptor (ER) isoform messenger RNA expression by different ER ligands in female rat pituitary. Biol Reprod 2004;70: 671-678.

25 Schausi D, Tiffoche C, Thieulant ML: Regulation of the intronic promoter of rat estrogen receptor- $\alpha$ gene, responsible for truncated estrogen receptor product-1 expression. Endocrinology 2003;144:2845-2855.

26 Vaillant C, Chesnel F, Schausi D, Tiffoche C, Thieulant ML: Expression of estrogen receptor subtypes in rat pituitary gland during pregnancy and lactation. Endocrinology 2002;143:4249-4258.

27 Mitchner NA, Garlick C, Steinmetz RW, Ben-Jonathan N: Differential regulation and action of estrogen receptors $\alpha$ and $\beta$ in GH3 cells. Endocrinology 1999;140:2651-2658.

28 Christian HC, Morris JF: Rapid actions of $17 \beta$-oestradiol on a subset of lactotrophs in the rat pituitary. J Physiol 2002;539:557-566.

29 Norfleet AM, Thomas ML, Gametchu B, Watson CS: Estrogen receptor- $\alpha$ detected on the plasma membrane of aldehyde-fixed $\mathrm{GH} 3 / \mathrm{B} 6 / \mathrm{F} 10$ rat pituitary tumor cells by enzyme-linked immunocytochemistry. Endocrinology 1999;140:3805-3814.

30 Gutiérrez S, De Paul AL, Petiti JP, del Valle Sosa L, Palmeri CM, Soaje M, Orgnero EM, Torres AI: Estradiol interacts with insulin through membrane receptors to induce an antimitogenic effect on lactotroph cells. Steroids 2008;73:515-527. 
-31 Zárate S, Jaita G, Zaldivar V, Radl DB, Eijo G, Ferraris J, Pisera D, Seilicovich A: Estrogens exert a rapid apoptotic action in anterior pituitary cells. Am J Physiol Endocrinol Metab 2009;296:E664-E671.

- 32 McDevitt MA, Glidewell-Kenney C, Jiménez MA, Ahearn PC, Weiss J, Jameson JL, Levine JE: New insights into the classical and nonclassical actions of estrogen: evidence from estrogen receptor knock-out and knock-in mice. Mol Cell Endocrinol 2008;290:24-30.

33 Micevych PE, Mermelstein PG: Membrane estrogen receptors acting through metabotropic glutamate receptors: an emerging mechanism of estrogen action in brain. Mol Neurobiol 2008;38:66-77.

-34 Madak-Erdogan Z, Kieser KJ, Kim SH, Komm B, Katzenellenbogen JA, Katzenellenbogen BS: Nuclear and extranuclear pathway inputs in the regulation of global gene expression by estrogen receptors. Mol Endocrinol 2008;22:2116-2127.

- 35 Freeman ME, Kanyicska B, Lerant A, Nagy G: Prolactin: structure, function, and regulation of secretion. Physiol Rev 2000;80: 1523-1631.

- 36 Day RN, Koike S, Sakai M, Muramatsu M, Maurer RA: Both Pit-1 and the estrogen receptor are required for estrogen responsiveness of the rat prolactin gene. Mol Endocrinol 1990;4:1964-1971.

-37 Nowakowski BE, Maurer RA: Multiple Pit-1binding sites facilitate estrogen responsiveness of the prolactin gene. Mol Endocrinol 1994;8:1742-1749.

- 38 Ying C, Lin DH, Sarkar DK, Chen TT: Interaction between estrogen receptor and Pit-1 protein is influenced by estrogen in pituitary cells. J Steroid Biochem Mol Biol 1999;68: 145-152.

-39 Watters JJ, Chun TY, Kim YN, Bertics PJ, Gorski J: Estrogen modulation of prolactin gene expression requires an intact mitogenactivated protein kinase signal transduction pathway in cultured rat pituitary cells. Mol Endocrinol 2000;14:1872-1881.

40 Ben-Jonathan N, Chen S, Dunckley JA, LaPensee C, Kansra S: Estrogen receptor- $\alpha$ mediates the epidermal growth factor-stimulated prolactin expression and release in lactotrophs. Endocrinology 2009; 150:795802.

-41 Giacomini D, Páez-Pereda M, Stalla J, Stalla GK, Arzt E: Molecular interaction of BMP-4, TGF- $\beta$, and estrogens in lactotrophs: impact on the PRL promoter. Mol Endocrinol 2009; 23:1102-1114.

-42 Kansra S, Yamagata S, Sneade L, Foster L, Ben-Jonathan N: Differential effects of estrogen receptor antagonists on pituitary lactotroph proliferation and prolactin release. Mol Cell Endocrinol 2005;239:27-36.
43 Kansra S, Chen S, Bangaru ML, Sneade L, Dunckley JA, Ben-Jonathan N: Selective estrogen receptor down-regulator and selective estrogen receptor modulators differentially regulate lactotroph proliferation. PLoS One 2010;5:e10060.

44 Pelletier G, Li S, Phaneuf D, Martel C, Labrie F: Morphological studies of prolactin secreting cells in estrogen receptor- $\alpha$ and estrogen receptor- $\beta$ knockout mice. Neuroendocrinology 2003;77:324-333.

45 Gellersen B, Kempf R, Telgmann R, DiMattia GE: Pituitary-type transcription of the human prolactin gene in the absence of Pit-1. Mol Endocrinol 1995;9:887-901.

$\checkmark 46$ Adamson AD, Friedrichsen S, Semprini S, Harper CV, Mullins JJ, White MR, Davis JR: Human prolactin gene promoter regulation by estrogen: convergence with tumor necrosis factor- $\alpha$ signaling. Endocrinology 2008; 149:687-694.

47 Watson CS, Norfleet AM, Pappas TC, Gametchu B: Rapid actions of estrogens in GH3/B6 pituitary tumor cells via a plasma membrane version of estrogen receptor- $\alpha$. Steroids 1999;64:5-13.

48 Bulayeva NN, Wozniak AL, Lash LL, Watson CS: Mechanisms of membrane estrogen receptor- $\alpha$-mediated rapid stimulation of $\mathrm{Ca}^{2+}$ levels and prolactin release in a pituitary cell line. Am J Physiol Endocrinol Metab 2005; 288:E388-E397.

49 Wozniak AL, Bulayeva NN, Watson CS: Xenoestrogens at picomolar to nanomolar concentrations trigger membrane estrogen receptor- $\alpha$-mediated $\mathrm{Ca}^{2+}$ fluxes and prolactin release in GH3/B6 pituitary tumor cells. Environ Health Perspect 2005;113:431-439.

-50 Bulayeva NN, Gametchu B, Watson CS: Quantitative measurement of estrogen-induced ERK-1 and -2 activation via multiple membrane-initiated signaling pathways. Steroids 2004;69:181-192.

51 Bulayeva NN, Watson CS: Xenoestrogen-induced ERK-1 and ERK-2 activation via multiple membrane-initiated signaling pathways. Environ Health Perspect 2004;112: 1481-1487.

52 Chowen JA, Frago LM, Argente J: The regulation of GH secretion by sex steroids. Eur J Endocrinol 2004;151:U95-U100.

-53 Childs GV, Iruthayanathan M, Akhter N, Unabia G, Whitehead-Johnson B: Bipotential effects of estrogen on growth hormone synthesis and storage in vitro. Endocrinology $2005 ; 146: 1780-1788$.

54 Childs GV, Unabia G, Wu P: Differential expression of growth hormone messenger ribonucleic acid by somatotropes and gonadotropes in male and cycling female rats. Endocrinology 2000;141:1560-1570.

55 Simard J, Hubert JF, Hosseinzadeh T, Labrie F: Stimulation of growth hormone release and synthesis by estrogens in rat anterior pituitary cells in culture. Endocrinology 1986; 119:2004-2011.
6 Dang VH, Choi KC, Jeung EB: Estrogen receptors are involved in xenoestrogen induction of growth hormone in the rat pituitary gland. J Reprod Dev 2009;55:206-213.

-57 Dang VH, Nguyen TH, Lee GS, Choi KC, Jeung EB: In vitro exposure to xenoestrogens induces growth hormone transcription and release via estrogen receptor-dependent pathways in rat pituitary GH3 cells. Steroids 2009;74:707-714

58 Iwasaki Y, Morishita M, Asai M, Onishi A, Yoshida M, Oiso Y, Inoue K: Effects of hormones targeting nuclear receptors on transcriptional regulation of the growth hormone gene in the $\mathrm{MtT} / \mathrm{S}$ rat somatotrope cell line. Neuroendocrinology 2004;79:229-236.

59 Melmed S: Mechanisms for pituitary tumorigenesis: the plastic pituitary. J Clin Invest 2003;112:1603-1618.

60 Nolan LA, Levy A: Prolonged oestrogen treatment does not correlate with a sustained increase in anterior pituitary mitotic index in ovariectomized Wistar rats. J Endocrinol 2009;200:301-309.

61 Sarkar DK: Genesis of prolactinomas: studies using estrogen-treated animals. Front Horm Res 2006;35:32-49.

62 Chaturvedi K, Sarkar DK: Alteration in G proteins and prolactin levels in pituitary after ethanol and estrogen treatment. Alcohol Clin Exp Res 2008;32:806-813.

63 Chun TY, Gregg D, Sarkar DK, Gorski J: Differential regulation by estrogens of growth and prolactin synthesis in pituitary cells suggests that only a small pool of estrogen receptors is required for growth. Proc Natl Acad Sci USA 1998;95:2325-2330.

64 Chen S, Bangaru ML, Sneade L, Dunckley JA, Ben-Jonathan N, Kansra S: Epidermal growth factor receptor cross-talks with ligand-occupied estrogen receptor- $\alpha$ to modulate both lactotroph proliferation and prolactin gene expression. Am J Physiol Endocrinol Metab 2009;297:E331-E339.

65 Paez-Pereda M, Giacomini D, Refojo D, Nagashima AC, Hopfner U, Grubler Y, Chervin A, Goldberg V, Goya R, Hentges ST, Low MJ, Holsboer F, Stalla GK, Arzt E: Involvement of bone morphogenetic protein- 4 in pituitary prolactinoma pathogenesis through a Smad/estrogen receptor crosstalk. Proc Natl Acad Sci USA 2003;100:1034-1039.

66 Watson CS, Jeng YJ, Kochukov MY: Nongenomic actions of estradiol compared with estrone and estriol in pituitary tumor cell signaling and proliferation. FASEB J 2008;22: 3328-3336.

67 Jeng YJ, Watson CS: Proliferative and antiproliferative effects of dietary levels of phytoestrogens in rat pituitary GH3/B6/F10 cells - the involvement of rapidly activated kinases and caspases. BMC Cancer 2009;9: 334. 
68 Yamakawa K, Arita J: Cross-talk between the estrogen receptor-, protein kinase A-, and mitogen-activated protein kinase-mediated signaling pathways in the regulation of lactotroph proliferation in primary culture. J Steroid Biochem Mol Biol 2004;88:123-130.

69 Gutiérrez S, Petiti JP, De Paul AL, Mukdsi JH, Aoki A, Torres AI, Orgnero EM: Antagonic effects of oestradiol in interaction with IGF-1 on proliferation of lactotroph cells in vitro. Histochem Cell Biol 2005;124:291301.

70 Ishida M, Takahashi W, Itoh S, Shimodaira S, Maeda S, Arita J: Estrogen actions on lactotroph proliferation are independent of a paracrine interaction with other pituitary cell types: a study using lactotroph-enriched cells. Endocrinology 2007;148:3131-3139.
71 Ishida M, Mitsui T, Izawa M, Arita J: Absence of ligand-independent transcriptional activation of the estrogen receptor via the estrogen response element in pituitary lactotrophs in primary culture. J Steroid Biochem Mol Biol 2010;118:93-101.

72 Seilicovich A: Cell life and death in the anterior pituitary gland: role of oestrogens. J Neuroendocrinol 2010;22:758-764.

73 Candolfi M, Zaldivar V, De Laurentiis A, Jaita G, Pisera D, Seilicovich A: TNF- $\alpha$ induces apoptosis of lactotropes from female rats. Endocrinology. 2002;143:3611-3617.

74 Jaita G, Candolfi M, Zaldivar V, Zárate S, Ferrari L, Pisera D, Castro MG, Seilicovich A: Estrogens up-regulate the Fas/FasL apoptotic pathway in lactotropes. Endocrinology 2005; 146:4737-4744.
75 Radl DB, Zárate S, Jaita G, Ferraris J, Zaldivar V, Eijo G, Seilicovich A, Pisera D: Apoptosis of lactotrophs induced by $\mathrm{D} 2$ receptor activation is estrogen dependent. Neuroendocrinology 2008;88:43-52.

76 Zaldivar V, Magri ML, Zárate S, Jaita G, Eijo G, Radl D, Ferraris J, Pisera D, Seilicovich A: Estradiol increases the expression of TNF- $\alpha$ and TNF receptor 1 in lactotropes. 2010 (submitted).

77 Zaldivar V, Magri ML, Zárate S, Jaita G, Eijo G, Radl D, Ferraris J, Pisera D, Seilicovich A: Estradiol increases the $\mathrm{Bax} / \mathrm{Bcl}-2$ ratio and induces apoptosis in the anterior pituitary gland. Neuroendocrinology 2009;90:292300 